\title{
Permanent volumizing and contouring of the lower face using 350 centistokes injectable silicone
}

\author{
Betul Gozel Ulusal \\ Department of Plastic Reconstructive and Aesthetic Surgery, Faculty of Medicine, Balikesir University, Balikesir 10145, Turkey.
}

Correspondence to: Prof. Dr. Betul Gozel Ulusal, Department of Plastic Reconstructive and Aesthetic Surgery, Faculty of Medicine, Balikesir University, Balikesir 10145, Turkey. E-mail: betul.ulusal@gmail.com

How to cite this article: Ulusal BG. Permanent volumizing and contouring of the lower face using 350 centistokes injectable silicone. Plast Aesthet Res 2018;5:7. http://dx.doi.org/10.20517/2347-9264.2017.81

Received: 27 Oct 2017 First Decision: 18 Jan 2018 Revised: 6 Feb 2018 Accepted: 10 Feb 2018 Published: 28 Feb 2018

Science Editor: Raúl González-García Copy Editor: Jun-Yao Li Production Editor: Cai-Hong Wang

\begin{abstract}
Aim: An ideal injectable material would be biocompatible with long-lasting effects. The relative polymerization and chain length of the compound determines its viscosity, as measured by centistokes (cp). It is available in 350, 1000 and 5000 $\mathrm{cp}$ - the higher the number, the more viscous the oil. Most of the reports used 1000-cp silicone oil for filling purposes and due to high viscosity, only microdroplet injection technique is recommended to avoid complications. This is the first report of patient series using liquid silicone with a 350-cp viscosity The objective of this study was to explore the reliability and efficacy of low viscosity liquid silicone for lower face contour correction.
\end{abstract}

Methods: Lower facial region of 43 patients including chin, nasolabial and melolabial regions were treated by low viscosity (350 cp) liquid silicone. Instead of microdroplet tehniqe, retrograde linear threading technique was used. Total injection volume was $6.0 \pm 3.9 \mathrm{~mL}$. At least two sessions were required for complete correction which are spaced one month apart. Overcorrection was avoided. The treated areas had a soft and natural feeling with no lumpiness and stiffness.

Results: Mean follow-up period was $16.8 \pm 14.3$ months. The mean aesthetic satisfaction score was 4.51. No migration of the material was seen which is revealed by palpation and no major complication was encountered. None of the patients had any complaints regarding late facial deformity due to silicone migration.

Conclusion: Low viscosity liquid silicone is effective, well-tolerated and easy to use. It can be used as an alternative to higher viscosity silicones to avoid technical errors and complications.

Keywords: Liquid silicone, injection, filler, lower face, augmentation, deep wrinkles, face contour, face volume

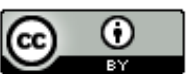

(C) The Author(s) 2018. Open Access This article is licensed under a Creative Commons Attribution 4.0 International License (https://creativecommons.org/licenses/by/4.0/), which permits unrestricted use, sharing, adaptation, distribution and reproduction in any medium or format, for any purpose, even commercially, as long as you give appropriate credit to the original author(s) and the source, provide a link to the Creative Commons license, and indicate if changes were made. 


\section{INTRODUCTION}

Age-specific changes in facial soft tissues and their effects on facial morphology has been clearly decribed elsewhere ${ }^{[1-3]}$. Restoration of soft tissue through augmentation, modify facial contours, correct tissue loss associated with normal aging. For over five decades, liquid injectable silicone has been used for soft-tissue augmentation ${ }^{[4-6]}$. It is believed that the historical complications and delayed type hypersentitivity reactions were due to the impurities of silicone products ${ }^{[7]}$. Modern highly purified silicone products are available in the current practice which allow safer applications. Highly purified liquid silicone is chemically pure, free of particulate matter, clear, colorless, odorless, tasteless, nonvolatile, viscosity-constant within the range of human body temperatures ${ }^{[8]}$. Silicone fluids range in viscosity from $0.65 \mathrm{cSt}$ (thinner than water) to more than $20,000,000 \mathrm{cSt}$ (thicker than chewing gum) $)^{[9]}$. The longer the polymer, the higher the viscosity. Viscosity does affect flow behavior and solubility. The higher the viscosity, the more slowly the polymer will flow and less soluble in some solvents ${ }^{[9]}$. Currently various silicone brands with different viscosities are available such as Biopolimero-350, Silikon-1000, AdatoSi 1-500, and Bioplastique. Usually liquid silicone with a 1000-centistokes (cp) viscosity has been used as a tissue filler ${ }^{[10-15]}$. Microdroplet serial puncture technique is currently considered to be a safe and efficacious tissue-biocompatible material for permanent intra- and subdermal implantation within the human body ${ }^{[10]}$.

There can be impressive results and significant complications associated with injectable silicone. Clark et al. ${ }^{[7]}$ in 1989 reviewed the safety of silicone injections and concluded that these complications are related primarily to the use of impure product, excess volumes, or inappropriate location.

\section{METHODS}

Forty-three patients were treated with liquid silicone (Biopolimero-350 cp, ZNK, Spain) between the years 2011 and 2016. An informed consent was obtained from each patient. Prior to treatment, the patients were fully informed of the precautions, method of administration, likely treatment responses, and potential adverse reactions. The procedures followed were in accordance with the ethical standards of the responsible committee on human experimentation.

All patients were female and mean age was $46 \pm 8$ years. No anesthetic or epinephrine was used. Before commencing injection, the skin was inspected for the presence of any dermatologic diseases, inflammation or infection (active acne, herpes simplex, etc.). All makeup were removed and the area was cleansed with an antiseptic. The areas to be augmented are marked with a pen with patients in a seated position under optimal lighting. No test for hypersensitivity was performed.

All injections were done subcutaneously through a $22-\mathrm{G}$ needle. Nasolabial, chin, cheek and melolabial areas were treated [Table 1]. The needle is inserted into the subcutanous plane with a 30-degree angle. The plunger of the syringe was pulled back and wait for a few seconds to see if the needle is in a blood vessels. The area to be treated is filled with liquid silicone by retrograde linear threading technique. While injecting the material, manual moderate pressure is applied with the the non-dominant hand index finger to control the depth of injection, to provide evenness and equal distribution of the liquid silicone. The injections were slowly performed and the needle is always moved to prevent embolic complications that could lead to tissue loss or blindness. The contour defects were deliberately undercorrected at the first session. Gradual augmentation was performed and at least 2 sessions were required for complete correction which are spaced 1 month apart. Optimal correction usually required 2 to 3 treatments. Usually the required volume for correction is reduced at the following sessions. No overcorrection was done. Cool compresses were recommended for $15 \mathrm{~min}$ immediately after the treatment to reduce redness, bruise and swelling. Topical ibuprofen (DolgitTM cream \%5, ADEKA) was commenced twice daily and continued for 1 week. Cosmetics were avoided for $24 \mathrm{~h}$. 
Table 1. Treated patients' demographics, treated regions, injected volume and follow-up periodsd

\begin{tabular}{|c|c|c|c|c|c|}
\hline No. & Age (year) & Treated region & Injection volume (mL) & $\begin{array}{l}\text { Total injected } \\
\text { volume }(\mathrm{mL})\end{array}$ & Follow up (month) \\
\hline 1 & 51 & $\mathrm{NL}$ & $3 /$ side & 6 & 8 \\
\hline 2 & 46 & $\mathrm{NL}$ & $2 /$ side & 4 & 2 \\
\hline 3 & 36 & $\mathrm{NL}$ & 1/side & 2 & 53 \\
\hline 4 & 48 & $\mathrm{NL}$ & 2/side & 4 & 13 \\
\hline 5 & 58 & $\mathrm{NL}$ & 3/side & 6 & 18 \\
\hline 6 & 53 & $\mathrm{NL}$ & 2.5/side & 5 & 5 \\
\hline 7 & 46 & $\mathrm{NL} /$ cheek & 2.5/3.5/side & 12 & 4 \\
\hline 8 & 64 & $\mathrm{NL} /$ melolabial & 3/2.5/side & 11 & 5 \\
\hline 9 & 56 & $\mathrm{NL} / \mathrm{chin}$ & 2/1.5/side & 7 & 45 \\
\hline 10 & 34 & $\mathrm{NL}$ & $1.5 /$ side & 3 & 51 \\
\hline 11 & 48 & NL & 2/side & 4 & 8 \\
\hline 12 & 63 & $\mathrm{NL} /$ cheek & $2.5 / 3 /$ side & 11.5 & 12 \\
\hline 13 & 67 & $\mathrm{NL}$ & 3.5/side & 7 & 16 \\
\hline 14 & 44 & NL & $1.5 /$ side & 3 & 38 \\
\hline 15 & 65 & $\mathrm{NL} /$ melolabial & 3/4/side & 14 & 7 \\
\hline 16 & 56 & $\mathrm{NL} /$ melolabial/cheek & $2 / 2 / 3 /$ side & 14 & 2 \\
\hline 17 & 47 & $\mathrm{NL} /$ cheek & $1.5 / 4 /$ side & 11 & 9 \\
\hline 18 & 45 & $\mathrm{NL}$ & $2 /$ side & 4 & 14 \\
\hline 19 & 42 & NL/cheek & 2/2/side & 8 & 4 \\
\hline 20 & 59 & $\mathrm{NL} / \mathrm{ML} /$ cheek & 2.5/2.5/3/side & 16 & 9 \\
\hline 21 & 41 & $\mathrm{NL}$ & 2/side & 4 & 6 \\
\hline 22 & 33 & Cheek (local) & 2 & 2 & 6 \\
\hline 23 & 40 & $\mathrm{NL}$ & $1.5 /$ side & 3 & 19 \\
\hline 24 & 36 & $\mathrm{NL}$ & $1 /$ side & 2 & 9 \\
\hline 25 & 39 & $\mathrm{NL}$ & $2 /$ side & 4 & 25 \\
\hline 26 & 35 & Cheek (one side) & 2 & 2 & 13 \\
\hline 27 & 39 & $\mathrm{NL}$ & $2 /$ side & 4 & 5 \\
\hline 28 & 43 & $\mathrm{NL}$ & $2 /$ side & 4 & 21 \\
\hline 29 & 41 & $\mathrm{NL} /$ cheek & $1 / 2 /$ side & 5 & 34 \\
\hline 30 & 45 & $\mathrm{NL}$ & $2 /$ side & 4 & 17 \\
\hline 31 & 44 & Cheek & 2/side & 4 & 49 \\
\hline 32 & 54 & NL/cheek & 2/4/side & 12 & 22 \\
\hline 33 & 36 & NL & 1/side & 2 & 2 \\
\hline 34 & 45 & $\mathrm{NL} /$ cheek & $1.5 / 3 /$ side & 9.5 & 42 \\
\hline 35 & 41 & $\mathrm{NL}$ & $2 /$ side & 4 & 24 \\
\hline 36 & 57 & $\mathrm{NL} /$ cheek & $3 / 3 /$ side & 12 & 22 \\
\hline 37 & 38 & $\mathrm{NL}$ & $1 /$ side & 2 & 30 \\
\hline 38 & 49 & NL/cheek & 2.5/3/side & 11 & 7 \\
\hline 39 & & $\mathrm{NL}$ & $1 /$ side & 2 & 11 \\
\hline 40 & 42 & $\mathrm{NL}$ & $1.5 /$ side & 3 & 12 \\
\hline 41 & 44 & NL/cheek & $1.5 / 1 /$ side & 5 & 12 \\
\hline 42 & 47 & $\mathrm{NL}$ & $1.5 /$ side & 3 & 10 \\
\hline 43 & 48 & $\mathrm{NL}$ & $2 /$ side & 4 & 3 \\
\hline
\end{tabular}

NL: nasolabial

Patients were photographed before the injection and at each visit. Before submission of this article, all patients were reached by phone and asked to rate their cosmetic and fuctional satisfaction on a 5-point scale: 1 - very dissatisfied; 2 - dissatisfied; 3 - neither satisfied nor dissatisfied; 4 - satisfied; 5 - very satisfied.

\section{RESULTS}

Mean follow-up period was $16.8 \pm 14.3$ months. The mean satisfaction score was 4.51 . Total injection volume was $6.0 \pm 3.9 \mathrm{~mL}$. No major complication was encountered. Only mild bruise was seen in 2 cases which faded within 1 week. Effective correction of the facial creases and smile lines were obtained [Figure 1]. Tissues remained 


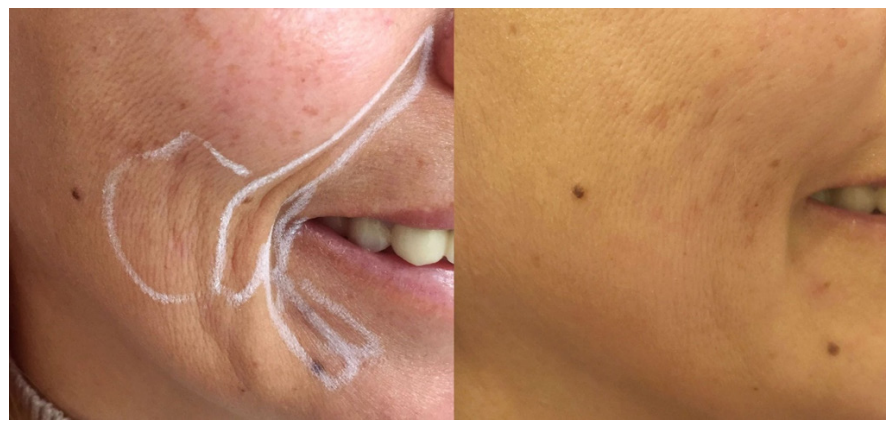

Figure 1. Effective correction of the facial creases and smile lines was achieved

soft, smooth and plump during the entire follow-up period [Figure 2]. None of the patients experienced late facial deformity, lump or other complications due to silicone migration. At the marionette and nasolabial creases, despite the ongoing process of aging, the results remained satisfactory for at least 1 year [Figure 3]. In patients with longer-term follow up (> 30 months), the deformity relapsed to an extent but no additional injections were demanded.

Since no overcorrection is done, the texture of soft tissue augmented with liquid silicone is usually natural with no irregularities, rubbery feeling or lumpiness.

\section{DISCUSSION}

Aging is not limited to the skin but also to its supporting structures. Atrophy of the subcutaneous adipose tissue, sagging skin due to loss of skin collagen lead to a loss of volume and change in facial contours. Facial creases (nasolabial, melolabial) progressively deepen, smile lines and periorbital lines become visible in the lower face ${ }^{[1-3]}$. In a young face superficial and deep fat is distributed evenly with smooth primary arcs and convexities. With age, the distribution of fat becomes altered by fat atrophy and hypertrophy producing hills and valleys with demarcations between the cosmetic units ${ }^{[16]}$.

Dermal and subcutaneous fillers, used either alone or as an adjunct to surgical and nonsurgical facial rejuvenation techniques, are a logical and effective treatment choice for "lifting and filling" the facial soft tissues $^{[17]}$. The aesthetic goal is to create a smooth transition between the units and to restore the ample, balanced distribution of facial fullness that exemplifies the youthful face ${ }^{[18]}$. The hills and valleys should be smoothed over and the former primary arcs and convexities of youth, rebuilt ${ }^{[19]}$.

Currently fat transfer, silicone and artefill are the choices for permanent facial augmentation, enhancement and rejuvenation. In my practice, I have been performing fat injection for the last 12 years. The outcomes depend on the number of the survived fat cells and this is partly technique and partly patient dependent; therefore usually the results are unpredictable. The operation takes time, requires at least 2 sessions, expensive and should be performed under strict sterile conditions. In the last 5 years, upon patients' demand, I have started using liquid silicone since I feel quite comfortable and skilled for filler applications. This alternative offers a rapid, practical and an effective way for patients who demand "permanent" facial volumizing and contour restoration.

Injectable liquid silicone has many qualities that could make it a suitable material for long-term softtissue augmentation. At the same time, there are still many unanswered questions pertaining to potential complications that need to be addressed before it can be considered for this purpose. 
A

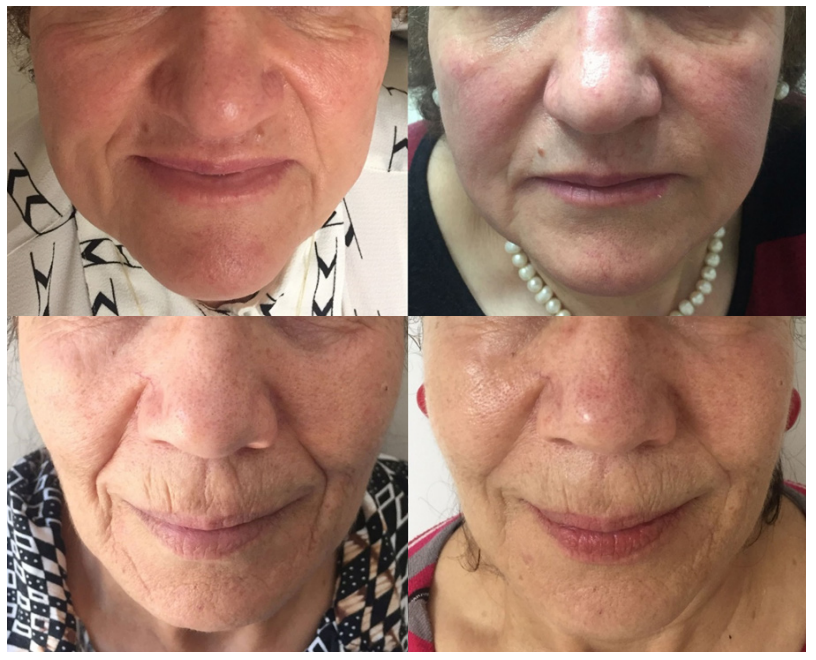

B

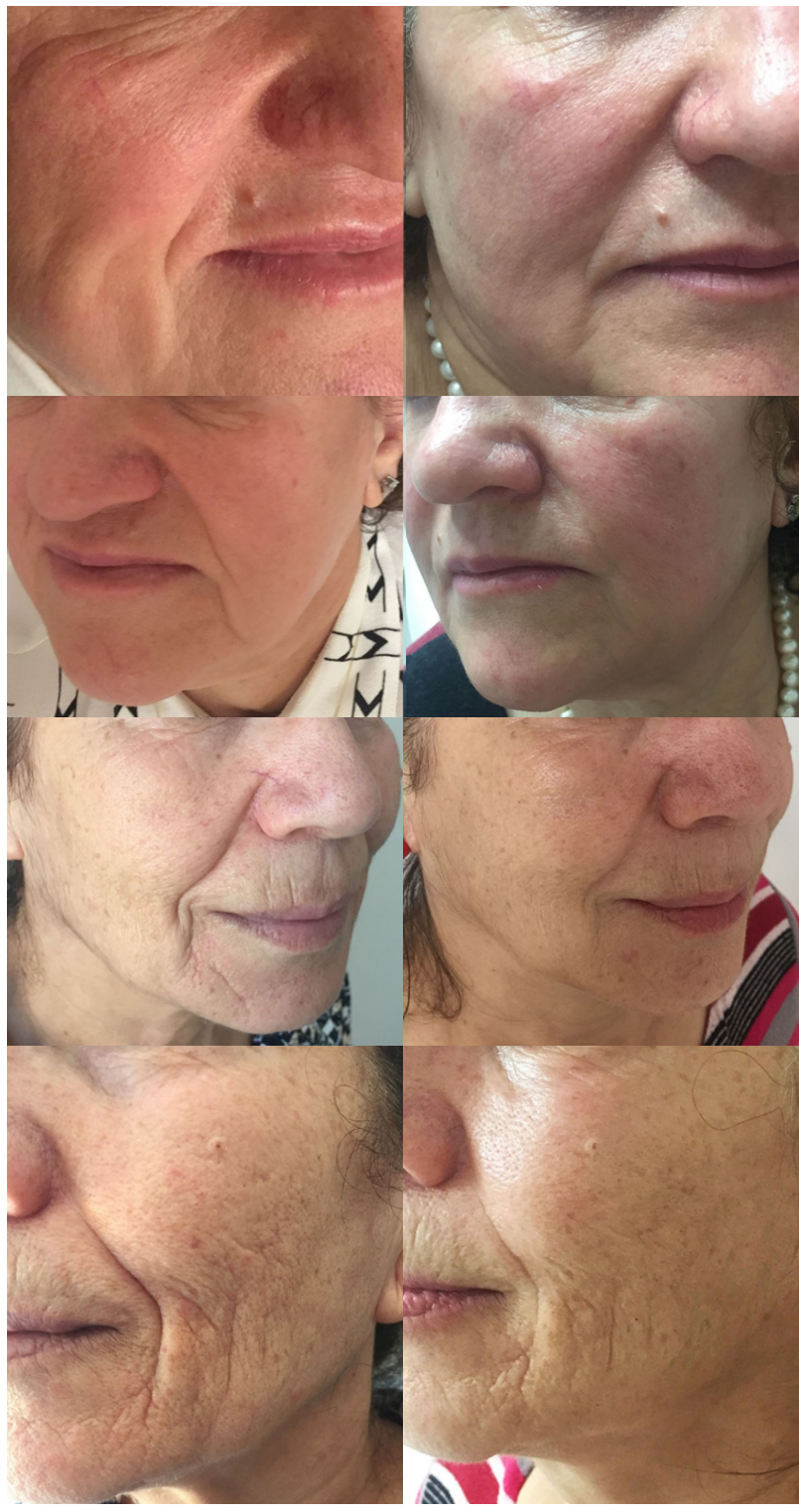

Figure 2. Restoration of smooth and soft facial contours, effective volumizing of the lower face. (A) Anterior view; (B) lateral view 


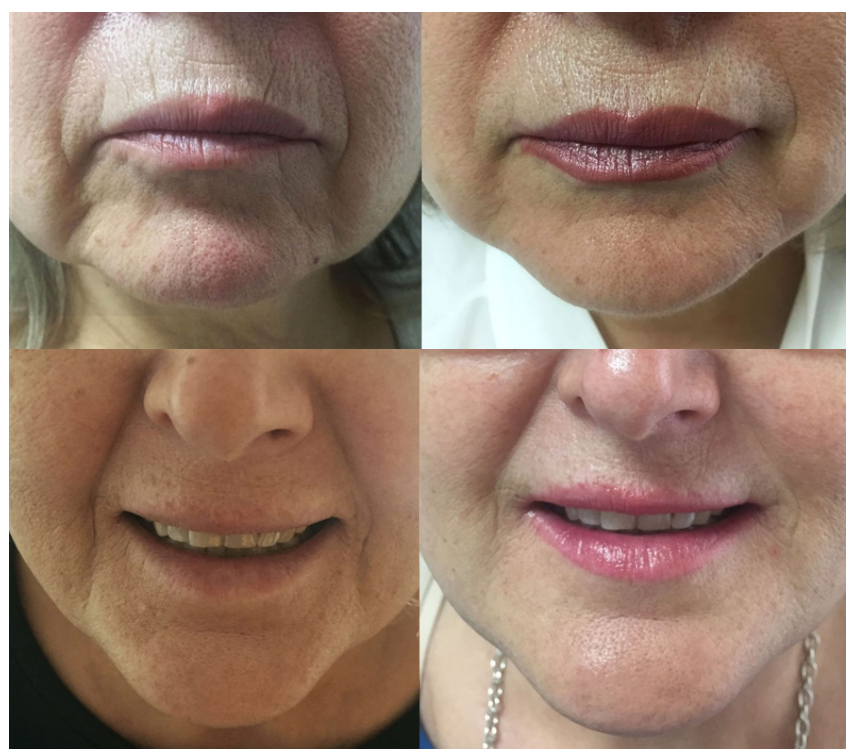

Figure 3. The improvement of the facial creases at 1 year

Currently, Food and Drug Administration-approved clinical trials are reported to be in progress for a liquid silicone product specifically for treatment of human immunodeficiency virus-associated facial lipoatrophy and for use in cosmetic indications ${ }^{[20]}$.

Little is known about the study except that it involves the use of a microdroplet serial puncture technique, as described by Orentreich ${ }^{[14]}$ and Orentreich ${ }^{[15]}$. This injection technique was reported in the late 1970s. It consists of depositing minute droplets of liquid silicone $0.01 \mathrm{~mL}$ or smaller into the subdermal tissues at 2 to $10 \mathrm{~mm}$ intervals. Injection of these microdroplets has been shown to produce a mild inflammatory reaction, resulting in a fibroblastic response. It is believed that this neocollagen synthesis is complete after approximately 3 months. The resulting fibrosis is responsible for the apparent soft-tissue augmentation. By contrast, injections of larger doses (greater than $0.05 \mathrm{~mL}$ ) has been shown to produce granulomas and foreign body reaction ${ }^{[7,14]}$.

In 1971, Ashley et al. ${ }^{[21]}$ presented hundreds of animal studies and followed 90 patients for 3 months, with excellent results. They did mention that it was important to use small volumes at each session. Their average volume per injection was $4 \mathrm{~mL}$, which was considered a small volume in the early 1970s. They also were the first to use higher viscosity silicones up to $1000 \mathrm{cS}$, noting that large volumes of low-viscosity silicones tended to migrate where the higher viscosity silicones did not migrate. As oppose to Ashley's report, we have not encountered migration even in a single case. The filler remained stable during the entire follow-up period. It may be the injection technique (linear line versus microdroplet) that prevented migration. New histological studies are required to reveal and compare the fibroblastic responses between the two techniques.

In linear threading technique, there are fewer needle punctures, and potentially a smoother result since it is easier to produce contiguous layering. A smooth and even deposition of the filler could be attained in our series. None of the patients complained of granuloma formation of filler beads.

In conclusion, lower viscosity of liquid silicone (350 cp) is effective and safe for correction of deep facial lines and contouring. It provides soft and smooth facial contours and effectively volumize the face. Retrograde linear threading technique seems a safe technique and migration is not a concern using silicone with $350 \mathrm{cp}$ viscosity. 
However since there are concerns about delayed hypersensitivity and late complications, in order to accept it as a universally safe method, further studies with longer follow-up periods are required.

\section{DECLARATIONS}

\section{Authors' contributions}

Ulusal BG contributed solely to the paper.

\section{Financial support and sponsorship}

None.

\section{Conflicts of interest}

There are no conflicts of interest.

\section{Patient consent}

An informed consent was obtained from each patient.

\section{Ethics approval}

The procedures followed were in accordance with the ethical standards of the responsible committee on human experimentation.

\section{Copyright}

(c) The Author(s) 2018.

\section{REFERENCES}

1. Kaur M, Garg RK, Singla S. Analysis of facial soft tissue changes with aging and their effects on facial morphology: a forensic perspective. Egypt J Forensic Sci 2015;5:46-56.

2. Ascher B, Coleman S, Alster T, Bauer U, Burgess C, Butterwick K, Donofrio L, Engelhard P, Goldman MP, Katz P, Vleggaar D. Full scope of effect of facial lipoatrophy: a framework of disease understanding. Dermatol Surg 2006;32:1058-69.

3. Friedman O. Changes associated with the aging face. Facial Plast Surg Clin North Am 2005;13:371-80.

4. Narins RS, Beer K. Liquid injectable silicone: a review of its history, immunology, technical considerations, complications, and potential. Plast Reconstr Surg 2006;118:S77-84.

5. Webster RC, Fuleihan NS, Gaunt JM, Hamdan US, Gaunt IM, Smith RC. Injectable silicone for small augmentations: twenty-year experience in humans. Am J Cosm Surg 1984;1:1-10.

6. Chasan PE. The history of injectable silicone fluids for soft-tissue augmentation. Plast Reconstr Surg 2007;120:2034-40, discussion 2041-3.

7. Clark DP, Hanke CW, Swanson NA. Dermal implants: safety of products injected for soft tissue augmentation. J Am Acad Dermatol 1989;21:992-8.

8. Mojsiewicz-Pieńkowska K, Jamrógiewicz M, Szymkowska K, Krenczkowska D. Direct human contact with siloxanes (silicones) safety or risk part 1. Characteristics of siloxanes (silicones). Front Pharmacol 2016;7:132.

9. Naim JO, Ippolito KM, Lanzafame RJ. The effect of molecular weight and gel preparation on humoral adjuvancy of silicone oils and silicone gels. Immunol Invest 1995;24:537-47.

10. Alam M, Danahey DG. Permanent injectables for soft-tissue augmentation: avoiding misinformation and a reprise of the breast implant debacle. Arch Facial Plast Surg 2005;7:370-3.

11. Jones DH, Carruthers A, Orentreich D, Brody HJ, Lai MY, Azen S, Van Dyke GS. Highly purified 1000-cSt silicone oil for treatment of human immunodeficiency virus-associated facial lipoatrophy: an open pilot trial. Dermatol Surg 2004;30:1279-86.

12. Benedetto AV, Lewis AT. Injecting 1000 centistoke liquid silicone with ease and precision. Dermatol Surg 2003;29:211-4.

13. Duffy DM. Silicone: a critical review. Adv Dermatol 1990;5:93-107, discussion 108-9.

14. Orentreich DS. Liquid injectable silicone techniques for soft tissue augmentation. Clin Plast Surg 2000;27:595-612.

15. Orentreich NO. Soft tissue augmentation with medical grade fluid silicone. In: Rubin LR, editor. Biomaterials in reconstructive surgery. St Louis (MO): Mosby; 1983. p. 859-81.

16. Carniol PJ, Ganc D, Klinger A. Evaluating the aesthetic patient. In: Carniol PJ, Monheit GD, editors. Aesthetic Rejuvenation Challenges and Solutions: A World Perspective Hardcover. Boca Raton, FL: CRC Press; 2009. p. 1-36. 
17. Rohrich RJ, Rios JL, Fagien S. Role of new fillers in facial rejuvenation: a cautious outlook. Plast Reconstr Surg 2003;112:1899-902.

18. Donofrio M. Fat distribution: a morphologic study of the aging face. Dermatol Surg 2000;26:1107-12.

19. Little JW. Volumetric perceptions in midfacial aging with altered priorities for rejuvenation. Plast Reconstr Surg 2000;105:252-66; discussion 286-9.

20. Coleman SR. Injectable silicone returns to the United States. Aesthetic Surg J 2001;21:576-8.

21. Ashley FL, Braley S, McNall EG. The current status of silicone injection therapy. Surg Clin North Am 1971;51:501-9. 